\title{
BMJ Open Birth control pills and risk of hypothyroidism: a cross-sectional study of the National Health and Nutrition Examination Survey, 2007-2012
}

\author{
Yuxuan Qiu (D) , ${ }^{1,2}$ Yuanyuan Hu, ${ }^{3,4}$ Zhichao Xing, ${ }^{2}$ Qingyu $\mathrm{Fu}^{3}{ }^{3}$ Jingqiang Zhu, ${ }^{2}$ \\ Anping $\mathrm{Su}^{2}$
}

To cite: Qiu Y, Hu Y, Xing Z, et al. Birth control pills and risk of hypothyroidism: a crosssectional study of the National Health and Nutrition Examination Survey, 2007-2012. BMJ Open 2021;11:e046607. doi:10.1136/ bmjopen-2020-046607

- Prepublication history and additional supplemental material for this paper are available online. To view these files, please visit the journal online (http://dx.doi.org/10.1136/ bmjopen-2020-046607).

$\mathrm{YQ}$ and $\mathrm{YH}$ contributed equally.

Received 04 November 2020 Accepted 01 June 2021

Check for updates

(c) Author(s) (or their employer(s)) 2021. Re-use permitted under CC BY-NC. No commercial re-use. See rights and permissions. Published by BMJ.

${ }^{1}$ Department of Ultrasound, West China Hospital, Sichuan University, Chengdu, China

${ }^{2}$ Center of Thyroid and Parathyroid Surgery, West China Hospital, Sichuan University, Chengdu, Sichuan, China

${ }^{3}$ West China School of Medicine, Sichuan University, Chengdu,

China

${ }^{4}$ Department of Obstetrics and Gynecology, West China Second Hospital, Sichuan University, Chengdu, Sichuan, China

Correspondence to

Dr Anping Su;

suanpingping@126.com

\section{ABSTRACT}

Objective The association between use of birth control pills and thyroid function in women has not ever been well studied, but potential risk has been implicated by small sample-sized studies. We aimed to determine this association using a large epidemiological survey.

Design Cross-sectional study.

Setting National Health and Nutrition Examination Survey conducted in the USA from 2007 to 2012.

Participants Female respondents aged 18+ who had data on history of taking birth control pills and thyroid function were included. History of taking birth control pills was based on responses on the reproductive health questionnaire. Participants not on antithyroid medication with thyroid-stimulating hormone (TSH) $>5.6 \mathrm{mlU} / \mathrm{L}$ and those on thyroid hormone replacement regardless of TSH were categorised as hypothyroid. Participants not on thyroid hormone replacement or antithyroid medication who had TSH between $0.34 \mathrm{mlU} / \mathrm{L}$ and $5.6 \mathrm{mlU} / \mathrm{L}$ were classified as euthyroid.

Primary and secondary outcome measures Association between use of birth control pills and hypothyroidism based on multivariate logistic regression analysis.

Results A total of 5116 female adults with history of taking birth control pills $(n=3034)$ and without $(n=2082)$ were included. A higher prevalence of hypothyroidism was found in those who have ever taken birth control pills $(17.7 \%$ vs $14.1 \% ; p=0.003)$. Multivariate logistic regression adjusted for confounding covariables, including age, race, education, body mass index, smoking status, alcohol use, history of thyroid disease, current thyroid disease, first menstrual age, pregnancy history, menopause status and history of hormone replacement use, demonstrated a significant association between history of taking birth control pills for more than 10 years and hypothyroidism (OR, 3.837; 95\% Cl 1.402 to 10.500 ; $\mathrm{p}=0.009$ ).

Conclusions Longer history of using birth control pills was strongly associated with hypothyroidism, especially for more than 10 years.

\section{INTRODUCTION}

Birth control pills have developed quickly and have been widely used by an increasing number of women of childbearing potential
Strengths and limitations of this study

- This study benefited from the large, nationally representative data set and rigorous research methods of the National Health and Nutrition Examination Survey.

- The study explored the association between oral contraception and hypothyroidism for the first time and controlled for important confounders.

- The limitations of this study were that data were derived from cross-sectional studies and that the relationship was not necessarily identified as causal. Use of self-reported data might result in recall bias.

since their introduction. ${ }^{1}$ As the most common form of effective and reversible contraception, the prevalence of use of birth control pills among women aged $15-45$ is $17 \%$ and $27.3 \%$ among all methods of contraception in the USA. Moreover, use of birth control pills declined as age increased: $54 \%$ of users of contraceptives were under 20 years old, $35 \%$ were $20-40$ years old, and only $11 \%$ were $40-45$ years old. ${ }^{2}$ Youth and popularisation of birth control pills warrant further research and investigation with regard to safety, especially long-term safety. Birth control pills were first designed to inhibit ovulation and are thus used for birth control. ${ }^{3}$ Over time, they did not only help prevent unwanted pregnancies but are also used as treatment for abnormal uterine bleeding, endometriosis, menstrual and hormonal disorder, etc. Additionally, long-term use of birth control pills ( $\geq 10$ years) could significantly decrease the risk of ovarian and endometrial cancer. ${ }^{4}$ However, they could also bring many adverse effects, including increased risk of hypertension, thromboembolic events, breast cancer, serious autoimmune diseases, and especially endocrine-related dysfunctions. ${ }^{56}$ 
Thyroid hormone, one of the most notable endocrine hormones, is crucial for normal growth, energy metabolism and reproduction. Hypothyroidism is the most common pathological hormone insufficiency, and without treatment may be associated with a high risk of morbidity and mortality. ${ }^{7}$ It lacks specific symptoms at the early stage, but can lead to systemic symptoms such as chills and fatigue as the disease progresses, and eventually presents as myxoedema or even heart failure. The prevalence of hypothyroidism in the USA is $4.6 \%$ according to the National Health and Nutrition Examination Survey (NHANES) III study. The prevalence is approximately three to seven times higher in women compared with men and its incidence increases with age. ${ }^{78}$ Several drugs could cause hypothyroidism, the most notable being lithium, amiodarone and tyrosine kinase inhibitors. $^{8}$ However, considering its higher incidence in women, there may be an association between medications commonly used by women and thyroid function. A literature review summarised two studies and reported that use of birth control pills was associated with a potentially higher risk of hypothyroidism. ${ }^{9}$ Strieder $e t a l^{10}$ reported ever use of contraceptives was possibly associated with hypothyroidism (relative risk [RR], 4.232; 95\% confidence interval [CI], 0.552 to 32.425 ) in a case-control study enrolling 29 cases. Similar trend was confirmed by Frank and Kay ${ }^{10}$ in their cohort study of 47 cases, showing an RR of 1.17 but a p value of 0.552 .

In other words, the relationship between use of birth control pills and hypothyroidism has been observed, but existing studies were limited by their sample size and follow-up duration. We examined the NHANES database, which is representative of the US population, to determine whether use of birth control pills was associated with a higher risk of hypothyroidism.

\section{MATERIALS AND METHODS}

\section{Patient and public involvement}

We conducted a retrospective analysis of a cohort of US population of the NHANES, a periodic survey performed by National Center for Health Statistics. Informed consent has been obtained from every participant and therefore there was no need for any ethical consent in this study. The NHANES includes extensive demographic data, physical examinations, laboratory tests, healthrelated questionnaires and lists of prescription medications. NHANES 2007-2012 is the only continuous survey that collects data on reproductive health and thyroid function laboratory tests among US women. We included women who had information about taking birth control pills in the reproductive health questionnaire, reported thyroid medication use and had thyroid function laboratory test values. In the reproductive health questionnaire, the main questions were 'Have you ever taken birth control pills?' and 'How long have you been taking birth control pills?', with the choices 'yes; no; refused or don't know', along with the exact number of years, respectively.
Knowledge of generic drug names was obtained from the prescription medications questionnaire, and the incidence of use of levothyroxine, methimazole and propylthiouracil was recorded. Thyroid-stimulating hormone (TSH) levels were determined through available data from thyroid profile tests using third-generation, two-site immunoenzymatic ('sandwich') assay (details in online supplemental file).

\section{Definitions of thyroid condition}

Thyroid condition was determined through patient report of currently taking medications and TSH tests in a manner similar to that of Thavaraputta $e t$ al, ${ }^{11} 12$ who reported the prevalence of thyroid disease in the USA using diagnostic criteria. NHANES documentation provides a reference range of $0.34-5.6 \mathrm{mIU} / \mathrm{L}$ for normal TSH based on manufacturer guidelines. Participants were determined to be hyperthyroid if they reported currently taking methimazole or propylthiouracil, regardless of TSH level, or if their TSH level was $<0.34 \mathrm{mIU} / \mathrm{L}$. If the remaining participants reported currently taking levothyroxine regardless of TSH level, or if their TSH level was $>5.6 \mathrm{mIU} / \mathrm{L}$, they were determined to be hypothyroid. Participants were determined to be euthyroid if they were included neither in the hyperthyroid nor hypothyroid group.

\section{Covariables and grouping}

Demographic information on age, race/ethnicity and education was recorded at the time of the interview. Body mass index (BMI) was coded into four categories based on standard cut-offs: underweight $\left(<18.5 \mathrm{~kg} / \mathrm{m}^{2}\right)$, normal BMI (from 18.5 to $<25 \mathrm{~kg} / \mathrm{m}^{2}$ ), overweight (from 25 to $\left.<30 \mathrm{~kg} / \mathrm{m}^{2}\right)$ and obese $\left(\geq 30 \mathrm{~kg} / \mathrm{m}^{2}\right)$. Smoking was coded into current, former or never, while alcohol use was coded into four categories from never up to three or more drinks per day. History and current knowledge of thyroid disease were also included.

Participants were divided into two groups according to whether they have ever taken birth control pills or not, as indicated on the reproductive health questionnaire. Participants with history of taking birth control pills were assigned to the history group; otherwise, they were assigned to no history group. Reproductive variables such as first menstrual age, pregnancy history, menopause status and history of hormone replacement use were included.

\section{Missing covariables}

The address of $11 \%$ of the participants could not be geocoded, which contributed to missing data in the cross-sectional analysis. As such, 10 multiple imputations using fully conditional specification were used to address potential biases arising from item non-response.

\section{Statistical analysis}

Statistical analyses were performed in StataSE V.14.2. $\chi^{2}$ tests were used in the descriptive tables on population characteristics; multivariate logistic regression was used 


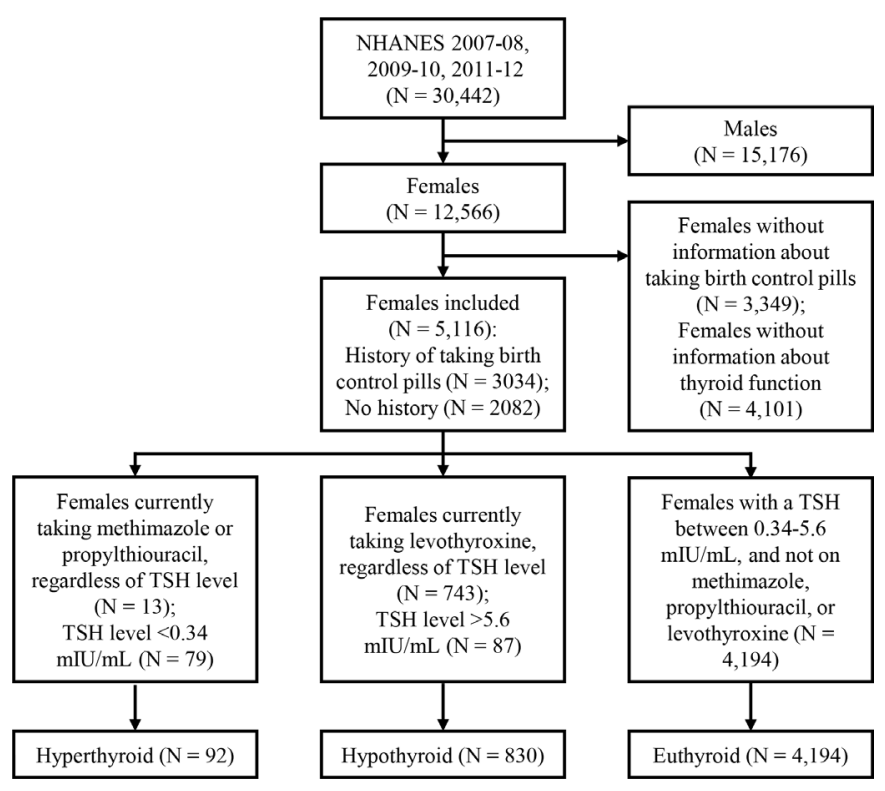

Figure 1 Schematic representation of participant selection and distribution of participant groups. NHANES, National Health and Nutrition Examination Survey; TSH, thyroidstimulating hormone.

to estimate the odds of a hypothyroid diagnosis among participants with history of taking birth control pills. Coefficients of logistic regression models presented include an unadjusted model; followed by model 1, adjusting for demographic covariables including age, race and education; model 2, adjusting for all covariates in model 1 , with individual covariables including BMI, smoking status, alcohol use, history of thyroid disease and current thyroid disease; and model 3, adjusting for all covariates in model 2, with gynaecological covariables including first menstrual age, pregnancy history, menopause status and history of hormone replacement use. History of taking birth control pills was subgrouped into history of $<1$ month, 1 month-1 year, 1-2 years, 2-10 years and $>10$ years. Statistical significance was set at $\mathrm{p}<0.05$.

\section{Patient and public involvement}

Patients and the public were not involved in the design of this study.

\section{RESULTS}

\section{Population characteristics}

The total number of participants in the 2007-2012 NHANES was 30442. Only 5116 female subjects met the inclusion criteria, including 2082 and 3034women who never took and were ever taking birth control pills, respectively (figure 1). Among the 3034 women who reported history of taking birth control pills, $210(6.9 \%)$ have taken birth control pills for less than 1 month, 864 (28.5\%) have a history of 1 month-1 year, $329(10.8 \%)$ of $1-2$ years, $1235(40.7 \%)$ of $2-10$ years, and $376(12.4 \%)$ of longer than 10 years. Table 1 lists the demographic and health characteristics of the history group and no history group. Younger women ( $<65$ years), non-Hispanic white women, participants with higher education, obese participants, currently smoking, higher alcohol consumption, history of pregnancy or current pregnancy, and participants with later first menstrual age were of higher proportions of history of taking birth control pills than their counterparts. Menopause status, age of last menstruation and use of hormone replacement medications including oestrogen and progestin (not including birth control pills) were not different between the two groups. Among the 5116 participants, 830 were identified as hypothyroid, 4194 as euthyroid and 92 as hyperthyroid. Participants in the history group more frequently developed a hypothyroid status $(17.7 \%$ vs $14.1 \%$; $p=0.003)$, with no difference in history or current knowledge of thyroid disease.

\section{Association between history of taking birth control pills and hypothyroidism}

According to univariate analysis, participants with any history of taking birth control pills carried an OR of 1.280 (95\% CI of 1.104 to 1.484) of developing hypothyroidism $(\mathrm{p}=0.001)$. Participants with history of $2-10$ years $(\mathrm{OR}$, 1.329; $95 \%$ CI 1.108 to $1.595 ; \mathrm{p}=0.002)$ and $>10$ years (OR, $1.865 ; 95 \%$ CI 1.440 to 2.415 ; $\mathrm{p}=0.000$ ) were more likely to have a hypothyroidism diagnosis. After adjusting for model 1 (demographic covariables including age, race and education), participants with any history of taking birth control pills remained at high risk of developing hypothyroidism (OR, 1.245; 95\% CI 1.043 to 1.486 ; $\mathrm{p}=0.015)$. Participants with history of 1 month-1 year (OR, 1.293; 95\% CI 1.021 to $1.636 ; \mathrm{p}=0.033$ ), $2-10$ years (OR, 1.262; 95\% CI 1.022 to $1.559 ; \mathrm{p}=0.030)$ and $>10$ years $(\mathrm{OR}, 1.555 ; 95 \%$ CI 1.167 to $2.072 ; \mathrm{p}=0.003)$ were at higher risk of developing hypothyroidism. However, after adjusting for model 2, adding individual covariables including BMI, smoking status, alcohol use, history of thyroid disease and current thyroid disease, women with history of taking birth control pills for more than 10 years were at a higher risk of developing hypothyroidism (OR, 4.025; $95 \%$ CI 1.489 to $10.879 ; \mathrm{p}=0.006$ ). Similarly, after adjusting for model 3, adding gynaecological covariables including first menstrual age, pregnancy history, menopause status, history of hormone replacement use and all variables in model 2, women with history of taking birth control pills for more than 10 years were at a higher risk of developing hypothyroidism (OR, 3.837; 95\% CI 1.402 to 10.500; $\mathrm{p}=0.009)$. All details are displayed in table 2. The association between history of taking birth control pills and hypothyroidism after excluding pregnant participants is shown in table 3. Similarly, after adjusting for model 3, history of taking birth control pills for more than 10 years was still associated with a higher risk of hypothyroidism (OR, 4.717; 95\% CI 1.721 to 12.926 ; $\mathrm{p}=0.003$ ).

\section{DISCUSSION}

To the best of our knowledge, this is the first study to reveal a strong association between long-term use of birth control pills and hypothyroidism. Based on a large 
Open access

Table 1 Demographic and clinical characteristics of the study population $(\mathrm{N}=5116)$

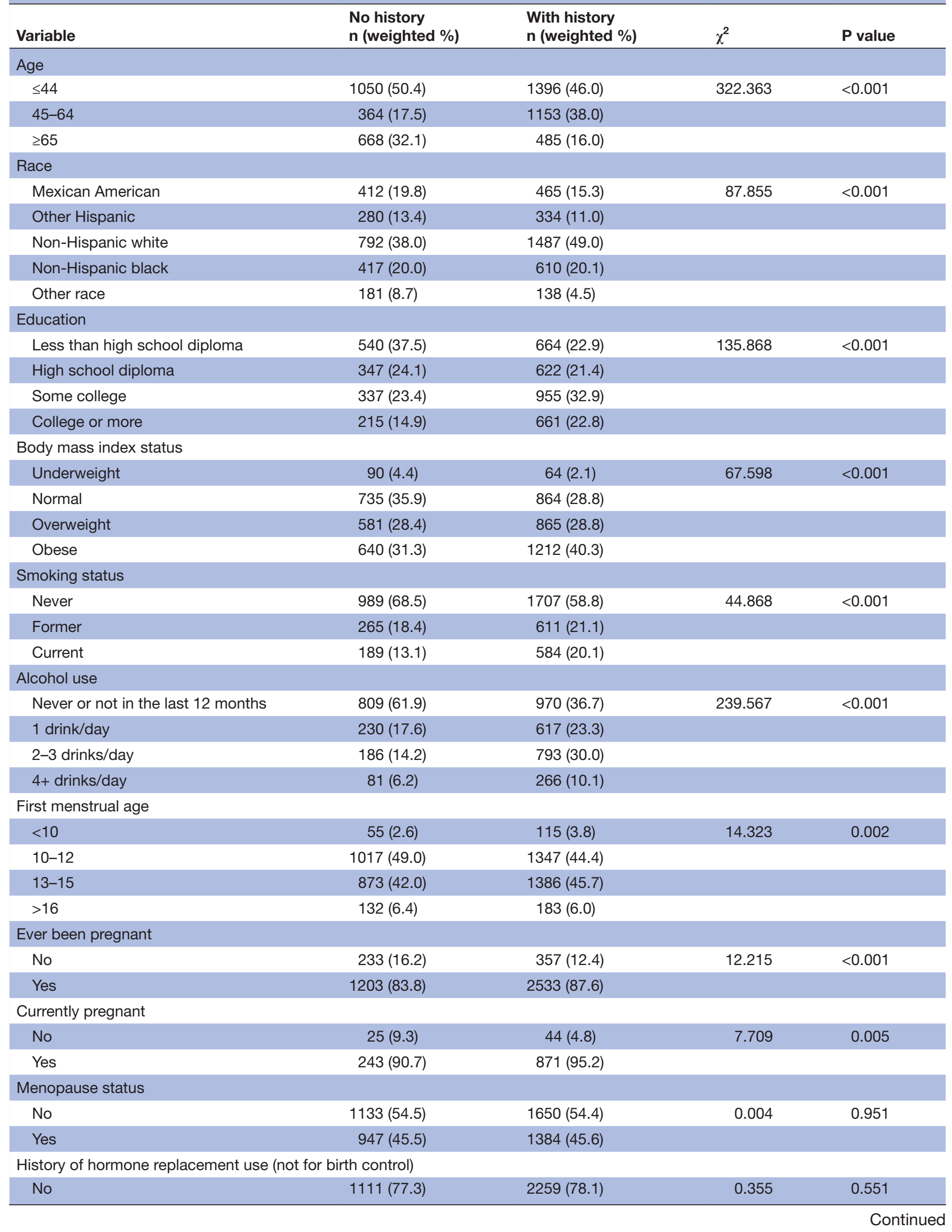


Table 1 Continued

\begin{tabular}{|c|c|c|c|c|}
\hline Variable & $\begin{array}{l}\text { No history } \\
\text { n (weighted \%) }\end{array}$ & $\begin{array}{l}\text { With history } \\
\text { n (weighted \%) }\end{array}$ & $\chi^{2}$ & $P$ value \\
\hline Yes & $326(22.7)$ & 633 (21.9) & & \\
\hline No & 1119 (77.5) & 2269 (78.4) & 0.388 & 0.534 \\
\hline Yes & 324 (22.5) & 626 (21.6) & & \\
\hline Yes & $254(79.4)$ & 503 (82.2) & & \\
\hline \multicolumn{5}{|l|}{ Thyroid status } \\
\hline Hyperthyroid & $37(1.8)$ & $55(1.8)$ & 11.507 & 0.003 \\
\hline Hypothyroid & $294(14.1)$ & $536(17.7)$ & & \\
\hline
\end{tabular}

number of participants in NHANES, the incidence of hypothyroidism increased significantly along with history of use of birth control pills even after adjustments. Participants with history of 1 month-1 year (OR, 1.293; 95\% CI 1.021 to $1.636 ; \mathrm{p}=0.033), 2-10$ years $(\mathrm{OR}, 1.262 ; 95 \% \mathrm{CI}$ 1.022 to $1.559 ; \mathrm{p}=0.030)$ and $>10$ years $(\mathrm{OR}, 1.555 ; 95 \% \mathrm{CI}$ 1.167 to $2.072 ; \mathrm{p}=0.003$ ) were at higher risk of developing a hypothyroid status, adjusting for demographic covariables including age, race and education. History of taking birth control pills for more than 10 years carried a significantly higher risk of hypothyroidism (OR, 3.837; 95\% CI 1.402 to $10.500 ; \mathrm{p}=0.009$ ) after adjusting for all considered variates including age, race, education, BMI, smoking status, alcohol use, history of thyroid disease, current thyroid disease, first menstrual age, pregnancy history, menopause status and medical use of hormone replacement. Birth control pills taking for over 10 years were burdened with higher susceptibility to hypothyroidism with or without excluding pregnant participants.

Some studies have investigated the relationship between birth control pills and hypothyroidism, but these were conducted differently. In 1978, Frank and Kay ${ }^{10}$ published the results of a cohort study of 23000 women currently taking contraceptive pills and a similar number of controls who have never taken contraceptive pills. The study lasted for 14 months and indicated oral contraceptives exerted a protective effect against thyroid myxoedema, with an RR of 0.57 . Vestergaard et $a l^{13}$ conducted a case-control study comprising 628 patients with autoimmune hypothyroidism and equal controls in an area with low iodine intake. The study suggested that ever use of oral contraceptives was associated with a slightly lower risk of Graves' disease in women, but not of autoimmune hypothyroidism. Another case-control study conducted by Strieder $\mathrm{et}^{14} \mathrm{l}^{14}$ held opposite opinion that neither ever use (OR, $4.20 ; 95 \%$ CI 0.55 to 32.43 ) nor current use (OR, $0.89 ; 95 \%$ CI 0.38 to 2.10 ) of oral contraception was associated with hypothyroidism. In a randomised control trial, 121 healthy women were observed for TSH and thyroxine after six cycles of use of combination oral contraceptives or progestin-only contraceptives, and both groups showed increased thyroxine-binding globulin, particularly for combination oral contraceptives. ${ }^{15}$ A retrospective study of 600 participants found use of oral contraceptives was a significant risk factor for accelerating hypothyroidism among pregnant women $(\mathrm{p}=0.0004) .{ }^{16}$ These conflicting conclusions may result from the limitations of follow-up duration, sample size and various confounding factors. This research especially addressed these data gaps.

Currently, birth control pills are available in different quantities. Combination oral contraceptives containing both oestrogen and progestin and progestin-only contraceptives are the two major types, which vary in their composition. ${ }^{3}$ Unfortunately, the abovementioned studies failed to provide details about birth control pills, and so did this questionnaire-based cross-sectional analysis. The prevalence of hypothyroidism in women is two to five times higher than in men, implying hormones could be involved in the disease course. ${ }^{817}$ However, the effects of progesterone or oestrogen only on thyroid function are less investigated and limited. Arafah ${ }^{18}$ included 36 postmenopausal women with or without hypothyroidism in a study and concluded that 12 weeks of oestrogen therapy could decrease thyroxine and worsen TSH in postmenopausal women with hypothyroidism treated with thyroxine. A 12-week randomised trial of oral micronised progesterone (progesterone, $300 \mathrm{mg} /$ day at bedtime) conducted by Sathi et $a l^{19}$ suggested that free thyroxine (FT4) levels were higher in placebo group, but TSH and free triiodothyronine levels were comparable. Caufriez et $a l^{20}$ found a reduction in TSH fluctuating with diurnal rhythmicity after a 3-week $300 \mathrm{mg}$ progesterone daily administration in eight postmenopausal women. TSH concentrations kept a relatively stable daytime levels, followed by an early evening circadian rise, a nocturnal decrease and a transient rebound after final morning awakening. These studies revealed fluctuations in TSH, but are still far from the boundary value after a short 

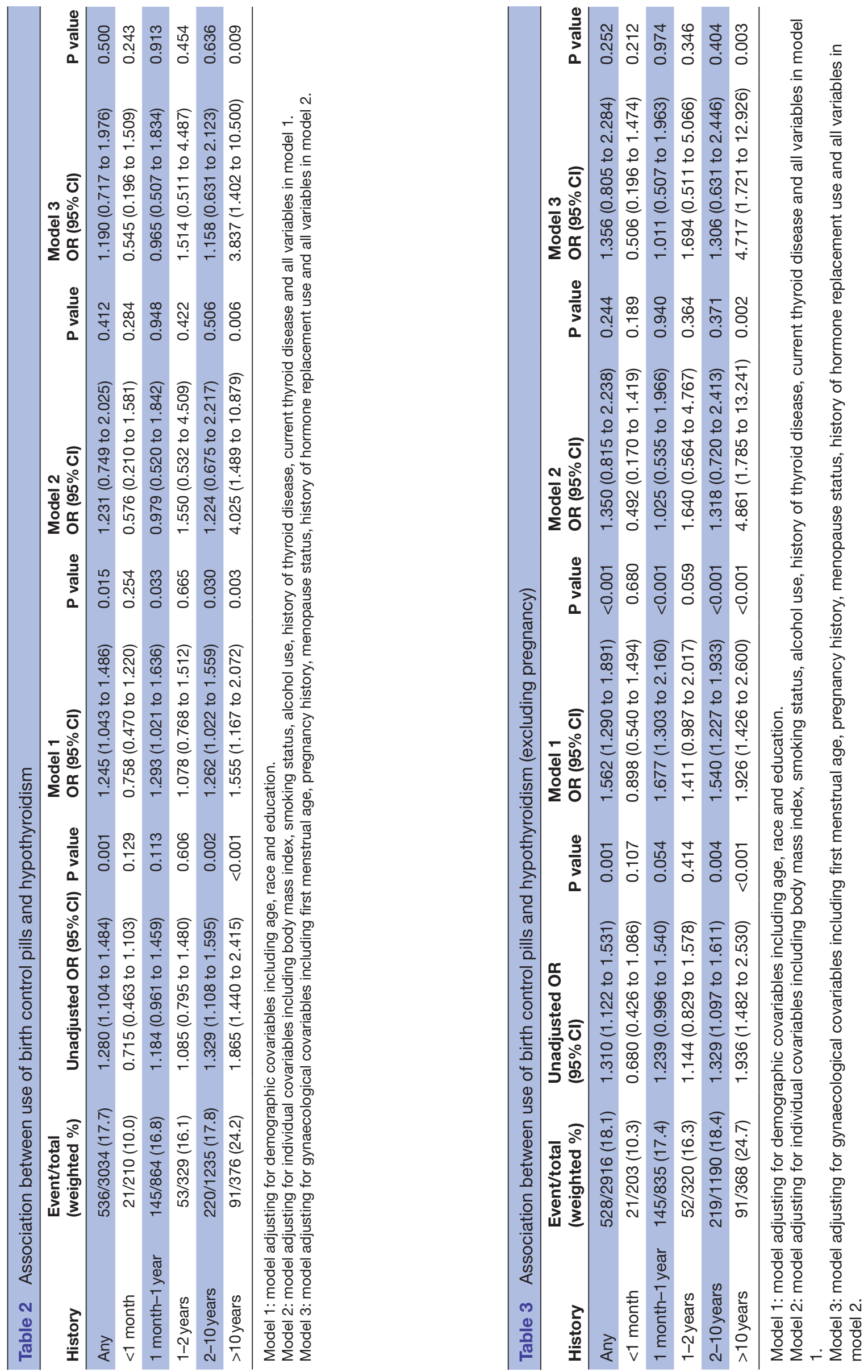
intervention. This echoed with our study that short-term use of birth control pills is not associated with hypothyroidism. Another study revealed significantly increased TSH (3.0 mIU/L vs $2.3 \mathrm{mIU} / \mathrm{L} ; \mathrm{p}<0.0001)$ and decreased FT4 (14.4 pmol $/ \mathrm{mL}$ vs $12.9 \mathrm{pmol} / \mathrm{mL} ; \mathrm{p}<0.0001)$, with elevated oestrogen and progesterone, followed by controlled ovarian hyperstimulation and especially a rapid 10-fold increase in oestrogen. ${ }^{21}$

Oestrogen and progesterone could also influence iodine uptake, whereas iodine deficiency is the main cause of hypothyroidism. ${ }^{8}$ Additionally, oestrogen could downregulate the expression of thyrotropin-releasing hormone mRNA in the paraventricular nucleus cells and upregulate the activity of thyroid peroxidase, resulting in a decrement in thyroxine synthesis, ${ }^{22}$ while progesterone could upregulate the expression of thyroglobulin, thyroperoxidase and sodium-iodide symporter mRNA in vitro. ${ }^{23}$ Moreover, oestrogen may increase women's susceptibility to thyroid disease by activation of the phosphatidylinositol 3-kinase (PI3K) pathway in the thyroid follicular cells. ${ }^{24}$ Oestrogen receptors are expressed in the majority of immune cells, and oestrogen can induce thyroid cell apoptosis, which may play a role in the high incidence of thyroid autoantibodies and autoimmune thyroid disease.$^{25}$ In order to minimise the confounding factors from other possible exposure of oestrogen and progestin, we calculated the primary outcomes after adjusting for first menstrual age, pregnancy history, menopause status and medical use of hormones.

In our study, a higher OR implied a higher risk of hypothyroidism as the extension of medication time. Hypothyroidism is a chronic pathophysiological process affected by inner and outer environmental balance. The internal environment homeostasis helps to process changes in oestrogen and progesterone administration through negative feedback. Therefore, a pathological thyroid will not occur due to changes in a short period of time, but will occur under long-term stimulation, such as taking birth control pills for over 10 years. The vast majority of cases of primary hypothyroidism were attributed to iodine deficiency and autoimmune disease (known as Hashimoto thyroiditis).$^{7826}$ Oestrogen and progesterone are regarded as disruptors of iodine absorption and are risk factors for Hashimoto thyroiditis. Most patients with Hashimoto thyroiditis can maintain normal thyroid function for a long time, and only a small number will show hyperthyroidism while the rest will end up with hypothyroidism. 82728

The demographic characteristics were quite different between participants with or without history of taking birth control pills. Generally, the differences in baseline characteristics could contribute to the non-comparability of outcomes between the two groups. However, it has been reported that the prevalence of TSH abnormalities increased with older age and lower socioeconomic status. ${ }^{29-31}$ That is to say, the differences in demographic characteristics could be associated with the development of hypothyroid status in our study. In addition, occupation, overweight, smoking and drinking are also significant risk factors for hypothyroidism. ${ }^{16} 32$ Therefore, we took all possible confounders into account by multivariate logistic regression rather than matching the variants due to the fact that the latter could reduce sample size.

Although our results are the first to reveal the significant association between history of taking birth control pills and hypothyroidism, specific medications for birth control were not available in the NHANES, which is the main limitation of our study. It is accepted that while use of oestrogen confers more susceptibility to hypothyroidism, the effects of progesterone on thyroid disorders merit further investigations. Second, overt and subclinical hypothyroidism were not distinguished in our study, because the levothyroxine supplement was adopted to most patients. Last but not the least, the cross-sectional nature of the study did not allow investigation of the causal relationship between birth control pills and hypothyroidism and this association might be affected by recall non-response bias.

In conclusion, our study used a large cohort of the US population to examine the association between history of taking birth control pills and hypothyroidism. Longer history of taking birth control pills was strongly associated with hypothyroidism, especially of more than 10 years. These findings have important implications for basic studies to determine whether there is a role for hypothyroid status and oral contraceptives.

Contributors Study conception and design: $Y Q, J Z$ and AS. Acquisition of data: $Y Q$ and QF. Analysis and interpretation of data: $Y Q$ and $Y H$. Drafting of the manuscript: $Y Q, Y H$ and ZX. Critical revision of the manuscript: JZ and AS.

Funding This study was supported by the 1.3.5 Project for Disciplines of Excellence, West China Hospital, Sichuan University (ZY2017309).

Competing interests None declared.

Patient consent for publication Not required.

Ethics approval Ethical approval was not applicable in this study.

Provenance and peer review Not commissioned; externally peer reviewed.

Data availability statement Data are available upon reasonable request.

Supplemental material This content has been supplied by the author(s). It has not been vetted by BMJ Publishing Group Limited (BMJ) and may not have been peer-reviewed. Any opinions or recommendations discussed are solely those of the author(s) and are not endorsed by BMJ. BMJ disclaims all liability and responsibility arising from any reliance placed on the content. Where the content includes any translated material, BMJ does not warrant the accuracy and reliability of the translations (including but not limited to local regulations, clinical guidelines, terminology, drug names and drug dosages), and is not responsible for any error and/or omissions arising from translation and adaptation or otherwise.

Open access This is an open access article distributed in accordance with the Creative Commons Attribution Non Commercial (CC BY-NC 4.0) license, which permits others to distribute, remix, adapt, build upon this work non-commercially, and license their derivative works on different terms, provided the original work is properly cited, appropriate credit is given, any changes made indicated, and the use is non-commercial. See: http://creativecommons.org/licenses/by-nc/4.0/.

ORCID iD

Yuxuan Qiu http://orcid.org/0000-0002-5467-6466 


\section{REFERENCES}

1 Benagiano G, Bastianelli C, Farris M. Contraception today. Ann N Y Acad Sci 2006;1092:1-32

2 Jones J, Mosher W, Daniels K. Current contraceptive use in the United States, 2006-2010, and changes in patterns of use since 1995. Natl Health Stat Report 2012;60:1-25.

3 Christin-Maitre S. History of oral contraceptive drugs and their use worldwide. Best Pract Res Clin Endocrinol Metab 2013;27:3-12.

4 Michels KA, Pfeiffer RM, Brinton LA, et al. Modification of the associations between duration of oral contraceptive use and ovarian, endometrial, breast, and colorectal cancers. JAMA Oncol 2018;4:516-21.

5 Benagiano G, Benagiano M, Bianchi P, et al. Contraception in autoimmune diseases. Best Pract Res Clin Obstet Gynaecol 2019;60:111-23.

6 Serfaty D. Update on the contraceptive contraindications. J Gynecol Obstet Hum Reprod 2019;48:297-307.

7 Chaker L, Bianco AC, Jonklaas J, et al. Hypothyroidism. Lancet 2017;390:1550-62

8 Taylor PN, Albrecht D, Scholz A, et al. Global epidemiology of hyperthyroidism and hypothyroidism. Nat Rev Endocrinol 2018;14:301-16.

9 Williams WV. Hormonal contraception and the development of autoimmunity: a review of the literature. Linacre Q 2017;84:275-95.

10 Frank P, Kay CR. Incidence of thyroid disease associated with oral contraceptives. Br Med J 1978;2:1531.

11 Thavaraputta S, Dennis JA, Laoveeravat P, et al. Hypothyroidism and its association with sleep apnea among adults in the United States: NHANES 2007-2008. J Clin Endocrinol Metab 2019;104:4990-7.

12 Kakigi C, Kasuga T, Wang SY, et al. Hypothyroidism and glaucoma in the United States. PLoS One 2015;10:e0133688.

13 Vestergaard P, Rejnmark L, Weeke J, et al. Smoking as a risk factor for Graves' disease, toxic nodular goiter, and autoimmune hypothyroidism. Thyroid 2002;12:69-75.

14 Strieder TGA, Prummel MF, Tijssen JGP, et al. Risk factors for and prevalence of thyroid disorders in a cross-sectional study among healthy female relatives of patients with autoimmune thyroid disease. Clin Endocrinol 2003;59:396-401.

15 Ågren UM, Anttila M, Mäenpää-Liukko K, et al. Effects of a monophasic combined oral contraceptive containing nomegestrol acetate and $17 \beta$-oestradiol in comparison to one containing levonorgestrel and ethinylestradiol on markers of endocrine function. Eur J Contracept Reprod Health Care 2011;16:458-67.

16 Momtazan M, Mohammadi MJ, Tabahfar R, et al. Risk factors accelerating hypothyroidism in pregnant women referred to health centers in Abadan, Iran. Data Brief 2017;14:15-19.

17 Koshigoe S, Kwok WK, Tubis A. Effects of perilymph viscosity on low-frequency intracochlear pressures and the cochlear input impedance of the cat. J Acoust Soc Am 1983;74:486-92.
18 Arafah BM. Increased need for thyroxine in women with hypothyroidism during estrogen therapy. $N$ Engl J Med 2001;344:1743-9.

19 Sathi P, Kalyan S, Hitchcock CL, et al. Progesterone therapy increases free thyroxine levels--data from a randomized placebocontrolled 12-week hot flush trial. Clin Endocrinol 2013;79:282-7.

20 Caufriez A, Leproult R, L'Hermite-Balériaux M, et al. Progesterone prevents sleep disturbances and modulates $\mathrm{GH}, \mathrm{TSH}$, and melatonin secretion in postmenopausal women. J Clin Endocrinol Metab 2011;96:E614-23.

21 Muller AF, Verhoeff A, Mantel MJ, et al. Decrease of free thyroxine levels after controlled ovarian hyperstimulation. J Clin Endocrinol Metab 2000;85:545-8.

$22 \mathrm{Wu}$ Y, Beland FA, Fang J-L. Effect of triclosan, triclocarban, $2,2^{\prime}, 4,4$ '-tetrabromodiphenyl ether, and bisphenol $A$ on the iodide uptake, thyroid peroxidase activity, and expression of genes involved in thyroid hormone synthesis. Toxicol In Vitro 2016;32:310-9.

23 Bertoni APS, Brum IS, Hillebrand AC. Progesterone upregulates gene expression in normal human thyroid follicular cells. Int $J$ Endocrinol 2015;2015:864852:6.

24 Antico-Arciuch VG, Dima M, Liao X-H, et al. Cross-Talk between PI3K and estrogen in the mouse thyroid predisposes to the development of follicular carcinomas with a higher incidence in females. Oncogene 2010;29:5678-86.

25 Wang SH, Myc A, Koenig RJ, et al. 2-Methoxyestradiol, an endogenous estrogen metabolite, induces thyroid cell apoptosis. $\mathrm{Mol}$ Cell Endocrinol 2000;165:163-72.

26 Caturegli P, De Remigis A, Rose NR. Hashimoto thyroiditis: clinical and diagnostic criteria. Autoimmun Rev 2014;13:391-7.

27 Ralli M, Angeletti D, Fiore M, et al. Hashimoto's thyroiditis: an update on pathogenic mechanisms, diagnostic protocols, therapeutic strategies, and potential malignant transformation. Autoimmun Rev 2020;19:102649.

28 Radetti G. Clinical aspects of Hashimoto's thyroiditis. Endocr Dev 2014;26:158-70.

29 Wilson S, Parle JV, Roberts LM, et al. Prevalence of subclinical thyroid dysfunction and its relation to socioeconomic deprivation in the elderly: a community-based cross-sectional survey. J Clin Endocrinol Metab 2006;91:4809-16.

30 Persani L. Clinical review: central hypothyroidism: pathogenic, diagnostic, and therapeutic challenges. J Clin Endocrinol Metab 2012;97:3068-78.

31 Lee J-M, Ha J, Jo K, et al. Risk factors for hypothyroidism in euthyroid thyroid nodule patients with lymphocytic thyroiditis on fine needle aspiration cytology. Korean J Intern Med 2019;34:1287-96.

32 Yasar HY, Topaloglu O, Demirpence M, et al. Is subclinical hypothyroidism in patients with polycystic ovary syndrome associated with BMI? Acta Endocrinol 2016;12:431-6. 